\title{
Pesticide residual characteristics in Strawberry, treated by drenching under hydroponics
}

\author{
Hyo-Sub Lee ${ }^{1}$ (D) $\cdot$ In-Seong Hwnag ${ }^{1} \cdot J^{\prime}$ e-In Cheon ${ }^{1} \cdot$ Hye-Young Kwon ${ }^{1}$. \\ Su-Myeong Hong ${ }^{1}$
}

\section{관주처리에 따른 양액재배 딸기의 농약잔류 특성}

\author{
이효섭 ${ }^{1} \cdot$ 황인성 $^{1}$ · 천재인 ${ }^{1}$ · 권혜영 ${ }^{1}$ · 홍수명 ${ }^{1}$
}

Received: 7 November 2018 / Accepted: 3 December 2018 / Published Online: 31 March 2019

(C) The Korean Society for Applied Biological Chemistry 2019

\begin{abstract}
Strawberries are one of the main commodities in Korea and have been exported over 40 million dollar. Because the strawberry cultivation using hydroponics has increased, treatment of pesticide by drenching draw interest recently. However, detailed researches for drenching treatment of pesticide are limited, which results in difficulties in proper pesticide applications in agricultural fields. To activate use of drenching and improve safety in agricultural products, In this study, time-dependent residual characteristic of pesticides were compared with between different applications of pesticides in strawberries. The characteristics of azoxystrobin, prochloraz and thiamethoxam were investigated with drenching treatment at different applications: the time of treatment, concentration etc. at hydroponic cultivation for 40 days. Azoxystrobin and prochloraz were not detected at 14 day after application. Thiamethoxam was detected from 0.02 to $0.85 \mathrm{mg} /$ $\mathrm{kg}$. Crop uptake of pesticides was strongly affected with octanolwater partition coefficient and solubility in water. Residual amount in crops are highly dependent on the concentration of active ingredient of pesticides.
\end{abstract}

Keywords Drenching $\cdot$ Hydroponic $\cdot$ Residual pesticide $\cdot$ Strawberry

Hyo-Sub Lee $(\triangle)$

E-mail:1hs8255@korea.kr

${ }^{1}$ Chemical Safety Division, Agro-Food Safety and Crop Protection Department, NAS, RDA, Wanju 55365, Republic of Korea

This is an Open Access article distributed under the terms of the Creative Commons Attribution Non-Commercial License (http://creativecommons. org/licenses/by-nc/3.0/) which permits unrestricted non-commercial use, distribution, and reproduction in any medium, provided the original work is properly cited.
서 론

딸기는 장미과에 속하는 다년초 작물로서 무기질, 비타민 $\mathrm{C}$ 가 풍부하고 항산화물질이 다량 함유되어 심혈관질환의 예방에 효 과적인 것으로 알려져 있는 과채류로서[1-3] 맛과 향이 좋아서 전 세계적으로 인기 있는 농산물로 자리매김 하고 있다[4]. 딸 기는 우리나라의 주요 수출작목으로 2017년 약 4,000만 달러 이상의 수출액을 기록하고 있다[5]. 최근에는 우리나라 딸기 재 배형태가 점적관수를 이용한 양액재배[6]로 빠르게 전환되고 있 고, 양액재배 비율은 ('08) 84.1 ha에서 ('14) 663.7로 증가하였 다[7]. 양액재배는 점적관수를 통해 상토에 양분과 수분을 공급 하여 작물이 뿌리를 통해 이를 흡수하게 하는 영농형태이다. 이 러한 영농형태는 온실 및 하우스에서 이루어져 재배환경이 온 난 다습하여 병 - 해충 피해가 많이 발생하여[8], 적정 수확량 생산을 위해서는 적절한 농약 사용이 가장 합리적인 방법이다. 양액재배 농가에서는 농약의 관주처리를 통해서 병-해충 방제 에 많은 관심을 가지고 있다. 농약 관주처리는 노동력 절감효 과가 있고, 뿌리에 피해를 주는 작은뿌리파리 및 탄저병 등 병· 해충 방제효과가 있고, 경엽처리에 비해서 잔류량이 낮게 $[9,10]$ 나타난다는 결과들이 있어 농민들의 관심을 받고 있다. 이러한 장점들이 있음에도 몇 가지 문제 때문에 제대로 이용되지 못하 고 있다.

첫째, 우리나라에 관주처리로 등록된 농약은 $5 \%$ 수준이다[5]. 농가 현장에서는 계속적으로 변하는 영농형태와 편의성 때문에 농약 관주처리는 계속적으로 사용하지만 합법적으로 사용할 수 있는 농약은 부족하다. 현장에서 관주처리로 많이 사용되는 약 제로는 azoxystrobin과 prochloraz로 근부탄저병 예방을 위해서 관주처리 하여 사용하지만, 농약 관주처리로 등록되지 않았다. 근부탄저병은 육묘기부터 발생하기 시작하고, 발병이 되면 위조 현상을 보이다가 고사하게 되는 병으로[11], 딸기에서 많이 발 
생하는 병이다. 매년 현장에서 활용하기 때문에 등록이 필요할 것으로 판단된다.

둘째, 수출 대상국을 기준으로도 관주처리로 등록된 농약비 율은 4-7\%로 매우 부족한데[12], 상대국 Maximum Residue Level (MRL)이 낮아 제대로 사용되지 못하고 있는 농약들이 있 다. Thiamethoxam은 그 중 대표적인 농약으로 우리나라 MRL $(1.0 \mathrm{mg} / \mathrm{kg})$ 보다 홍콩 MRL $(0.5 \mathrm{mg} / \mathrm{kg})$ 낮게 설정 되어있다. 홍콩은 우리나라 딸기의 최대 수출국으로[13], 많은 농가에서 홍콩 수출을 대상으로 딸기를 생산하고 있다. 또한 Thiamethoxam 은 작은뿌리파리 예방 약제로서, 작은뿌리파리는 시설육묘장에 서 연중 발생하여 피해를 주고, 특히 날씨가 따뜻해질 때 피해 가 심한 해충으로[14], 작은뿌리파리 방제를 위해 thiamethoxam 의 사용은 필요한 실정이다. 그러나, 상대 MRL이 낮은 경우 그 기준에 맞는 농약안전사용기준이 없기 때문에, 수출 농가에 서는 부적합 문제로 사용을 지양하고 있다. 농산물 수출시 $1 \%$ 의 안전성 사고는 농산물 수출에서 샘플 전수검사 및 수출금지 조치로 인해 큰 경제적 손실을 발생할 수 있기 때문이다. 그렇 기 때문에 수출 농가에서 수출확대를 위해서는 상대국 기준에 맞는 농약안전사용기준 설정이 필요하다.

이번 연구에서는 두 가지 현장 문제해결의 위해서, 등록이 되 지 않았지만 관행적으로 많이 사용하고 있는 농약 azoxystrobin 과 prochloraz의 잔류안전성 구명과 thiamethoxam의 다양한 관 주처리 조건을 통한 수출 상대국(홍콩) MRL에 맞는 농약안전 사용기준을 제시하고자 한다.

\section{재료 및 방법}

\section{농약표준용액 및 시약}

시험 농약은 딸기에 등록되어 있는 침투이행성 농약 3 종 (azoxystrobin, prochloraz, thiamethoxam)을 선정하였다.

분석에 사용한 표준품은 $\mathrm{Dr}$. Ehrenstorfer $\mathrm{GmbH}$ (Ausberg, Germany)에서 구매하여 사용하였고, 각각의 농약은 acetonitrile 으로 $1,000 \mathrm{mg} / \mathrm{L}$ 의 stock solution을 제조한 다음 이를 희석하 여 $10 \mathrm{mg} / \mathrm{L}$ 의 혼합 working solution을 제조하였다.

분석에 사용한 용매 acetonitrile, glacial acetic acid (100\%) 는 Merck사 (Darmstadt, Germany)의 HPLC Grade를 사용하 였고, formic acid ( $>98 \%$ purity)와 ammonium acetate $(99 \%$ purity)는 Sigma Aldrich (St. Louis, MS, USA)에서 구입하여 사용하였다. 3차 증류수는 Millipore사의 Milli-Q system (Bedford, USA)을 사용하여 제조하였다. QuEChERS 전처리를 위한 시약 및 제품은 Agilent (California, CF, USA)에서 구입 하였고, 추출 및 정제에는 Agilent QuEChERS Extract Kit AOAC 2007. 01 (6 g $\mathrm{MgSO}_{4}, 1.5 \mathrm{~g}$ sodium acetate $\left.(\mathrm{NaOAc})\right)$ 와 Agilent QuEChERS dispersive SPE $2 \mathrm{~mL}$ fatty and wax $\left(150 \mathrm{mg} \mathrm{MgSO}_{4}, 50 \mathrm{mg}\right.$ primary secondary amine, $50 \mathrm{mg}$ $\mathrm{C}_{18}$ )을 사용하였다.

\section{시험작물 및 포장시험}

딸기는 '매향'(Fragarid X ananassa Duch 'Maehyang') 품종으 로 경남 사천시에서 thiamethoxam과, 전북 완주군에서 azoxystrobin과 prochloraz-manganese를 이용하여 시설 양액재배
농가에서 시험을 진행하였다(Table 1). 시험기간은 2017년 5월 1 일부터 6월 10 일까지 진행하였다. 시험농약은 azoxystrobin $21.7 \%$ 액상수화제(상표명: 오티바), prochloraz-manganese $50 \%$ 수화제(상표명: 스포르곤) 및 thiamethoxam $10 \%$ 입상수화제(상 표명: 아타라)를 이용하였다. 시험조건은 농도, 살포횟수 및 살 포물량을 다르게 하여 처리하였고, 농약을 근부 부위에 투여하 였다. 딸기에 시험농약 살포조건으로 azoxystrobin은 2000배 희 석을 한 후 7일 간격으로 2회(수확7-0일 전), 3회(14-7-0일 전) 관주처리하였고, 농약 최종살포 2 시간 후 샘플을 채취하였다. Prochloraz-manganes는 2000배 희석하여 7일 간격으로 2회(수확 7-0일 전)살포하였고, 살포물량을 $50 \mathrm{~mL}$ 주, $100 \mathrm{~mL}$ 주로 하여 잔류량을 비교하였다. Thiamethoxam은 10 일 간격으로 2회(수확 10-0일 전)살포하였고, 살포농도(희석배수 $500,1000,2000$ 배)와 살포물량 $(50 \mathrm{~mL}$ 주, $100 \mathrm{~mL}$ 주)을 달리하여 처리구별로 잔류량 을 비교하였다. 시료채취 시기는 azoxystrobin, prochlorazmanganese는 0 (2시간 후), 7, 14, 24, 40일, thiamethoxam은 $0,7,21$ 일에 병 - 해충 피해가 없고 상품성이 있는 딸기를 1.5 $\mathrm{kg}$ 이상 채취하였고, 시험샘플은 꼭지를 제거한 딸기를 폴리에틸 렌 비닐에 담은 후 신속히 실험실로 운반하여 분석까지 $-20{ }^{\circ} \mathrm{C}$ 이하에서 보관하였다. 잔류농약 분석 전 시험샘플을 드라이아이 스와 함께 분쇄하여 분석샘플로 이용하였다.

\section{딸기 중 azoxystrobin 분석법}

딸기 $15 \mathrm{~g}$ 을 $50 \mathrm{~mL}$ plastic tube에 칭량 후 $15 \mathrm{~mL} 1 \%$ acetic acid가 포함된 acetonitrile를 첨가한 후 $1300 \mathrm{rpm}$ (1600 MiniG, SPEX sample Prep, Metuchen, NJ, USA) 5분 동안 진탕하였 다. 진탕 후 Agilent QuEChERS Extract kit AOAC 2007. 01 (6 g magnesium sulfate $\left(\mathrm{MgSO}_{4}\right), 1.5 \mathrm{~g}$ sodium acetate $(\mathrm{NaOAc})$ 를 첨가한 후 $1300 \mathrm{rpm}, 30$ 초간 흔든 다음 $3500 \mathrm{rpm}$ (Combi-514R, Hanil, Gimpo, Korea)에서 5분간 원심분리하여 상징액 $8 \mathrm{~mL}$ 를 취하였다. 상징액 $8 \mathrm{~mL}$ 를 Agilent QuEChERS dispersive kit $15 \mathrm{~mL}\left(1200 \mathrm{mg} \mathrm{MgSO}_{4}, 400 \mathrm{mg} \mathrm{PSA}\right)$ 에 첨가 한 후 2분간 voltex mixer를 이용하여 흔든 다음 $3500 \mathrm{rpm}, 5$ 분간 원심분리 하였다. 원심분리한 시료 $4 \mathrm{~mL}$ 를 취하여 감압농 축 후 $5 \mathrm{~mL} \mathrm{n}$-hexane : acetone $(95: 5, \mathrm{v} / \mathrm{v})$ 혼합용매로 재용해 하였다. Florisil (FL) cartridge $(1 \mathrm{~g})$ 을 이용하여 SPE 정제작업 을 진행하였다. FL cartridge에 n-hexane으로 $5 \mathrm{~mL}$ 로 conditioning 한 후, 시료 추출액 $5 \mathrm{~mL}$ 를 loading하고, 1차 전개액(n-hexane : acetone $=90: 10, \mathrm{v} / \mathrm{v}$ )을 $5 \mathrm{~mL}$ 흘려버리고, 2차 전개액(n-hexane : acetone $=70: 30, \mathrm{v} / \mathrm{v}) 20 \mathrm{~mL}$ 를 이용하여 용출하였다. 용출액을 $40{ }^{\circ} \mathrm{C}$ 이하에서 감압농축하여 $10 \mathrm{~mL}$ acetonitrile로 재용해 한 후 UHPLC/PDA를 Table 1과 같은 조건으로 분석하였다.

\section{딸기중 prochloraz 및 thiamethxam과 대사물질 분석법} 딸기 중 $\mathrm{QuEChERS} \mathrm{분석법은} \mathrm{Kwon[15]} \mathrm{및} \mathrm{Kim}$ 등[16]의 연 구를 참고하여 실시하였다. 딸기 $15 \mathrm{~g}$ 샘플을 $0.1 \%$ formic acid 가 포함된 acetonitrile $15 \mathrm{~mL}$ 를 첨가하여 $1300 \mathrm{rpm}$ 에서 5 분간 추출한 후 $4 \mathrm{~g} \mathrm{MgSO}_{4}, 1 \mathrm{~g} \mathrm{NaCl}, 1 \mathrm{~g} \mathrm{NaCitrate}, 0.5 \mathrm{~g}$ disodium citrate sesquihydrate를 첨가한 후 30 초가 진탕 후 $3500 \mathrm{rpm}$ 에 서 5 분간 원심분리 하였다. 위의 상등액 $1 \mathrm{~mL}$ 을 취하여 150 $\mathrm{mg} \mathrm{MgSO}_{4}, 25 \mathrm{mg}$ PSA (Primary Secondary Amino)이 첨가 된 $2 \mathrm{~mL}$ tube에 첨가한 후 $12000 \mathrm{rpm}$ 에서 5 분간 원심분리 한 
Table 1 UHPLC-PDA conditions for analyzing the pesticides

\begin{tabular}{ll}
\hline \hline Instrument & UHPLC-PDA (Shimadzu Nexera X2, Japan) \\
\hline Column & Shim-pack GIS-ODS $3 \mu \mathrm{m}, 100 \times 0.3 \mathrm{~mm}$ id \\
Solvents & Water/Acetonitrile $=50: 50(\mathrm{v} / \mathrm{v})$ \\
Temperature & $40{ }^{\circ} \mathrm{C}$ \\
Analysis time & $10 \mathrm{~min}$ \\
Wavelength & $254 \mathrm{~nm}$ \\
Injection volume & $5 \mu \mathrm{L}$ \\
Flow rate & $0.4 \mathrm{~mL} / \mathrm{min}$ \\
\hline
\end{tabular}

Table 2 HPLC-MS/MS conditions for analyzing the pesticides

\begin{tabular}{|c|c|c|c|}
\hline Instrument & \multicolumn{3}{|c|}{ Agilent $1200 \mathrm{HPLC}$ with Agilent 6410 triple-quadrupole Ms } \\
\hline Column & \multicolumn{3}{|c|}{ YMC-Pack Pro $\mathrm{C}_{18}$ RS $(100 \times 3$ mm I.d. 3 ìm $)$} \\
\hline Mobile phase & \multicolumn{3}{|c|}{$\begin{array}{l}\text { A: Water with } 0.1 \% \text { formic acid } \\
\text { B: Acetonitrile with } 0.1 \% \text { formic acid }\end{array}$} \\
\hline \multirow[t]{2}{*}{ Gradient table } & Time (min) & $\mathrm{A}(\%)$ & $\mathrm{B}(\%)$ \\
\hline & $\begin{array}{c}0 \\
2 \\
7 \\
8 \\
11\end{array}$ & $\begin{array}{l}95 \\
30 \\
30 \\
95 \\
95\end{array}$ & $\begin{array}{c}5 \\
70 \\
70 \\
5 \\
5\end{array}$ \\
\hline $\begin{array}{l}\text { Flow rate } \\
\text { column temp. } \\
\text { Injection volume } \\
\text { Ionization mode } \\
\text { Scan type }\end{array}$ & $\begin{array}{l}0.4 \mathrm{~mL} / \mathrm{min} \\
40^{\circ} \mathrm{C} \\
\mathrm{e} 10 \mu \mathrm{L} \\
\text { ESI Positive } \\
\text { MRM }\end{array}$ & $\begin{array}{l}\text { Ionspray voltage } \\
\text { nebulizer gas pressure } \\
\text { gas flow } \\
\text { gas temp. } \\
\text { Run time }\end{array}$ & $\begin{array}{l}4,000 \mathrm{~V} \\
50 \mathrm{psi} \\
10 \mathrm{~L} / \mathrm{min} \\
350^{\circ} \mathrm{C} \\
24 \mathrm{~min}\end{array}$ \\
\hline
\end{tabular}

후 상등액 $0.5 \mathrm{~mL}$ 를 취하여 $0.2 \mu \mathrm{m}$ syringe filter를 통과시킨 후 $0.5 \mathrm{~mL}$ acetonitrile 과 합친 후 vial에 넣은 후 LC-MS/MS 로 Table 2, 3와 같은 조건으로 분석하였다. Clothianidin은 Thiamethxam의 대사물질로서 Thiametthoxam과 동시에 분석을 하였다. Thiamethoxam의 총 잔류량은 농약 잔류분 정의(RDA 2012)를 참고하여 thiamethoxam과 clothianidin의 잔류량 합으로 계산하였다.

\section{표준검량선 작성 및 희수율 시험}

시험농약 4종 azoxystrobin, clothianidin, thiamethoxam 및 prochloraz를 Dr. Ehrenstorfer GmbH (Ausberg, Germany)에서 구매 후 acetonitrile으로 $1,000 \mathrm{mg} / \mathrm{L}$ 의 stock solution을 제조하 였다. 준비한 stock solution을 acetonitrile로 $10 \mathrm{mg} / \mathrm{L}$ working solution 제조하였다. 제조한 working solution을 이용하여 LC는 $0.05,0.1,0.2,0.5,1.0,2.0,5.0 \mathrm{mg} / \mathrm{L}$ 용액을 acetonitrile로 희석하여, LC-MS/MS는 $0.01,0.05,0.1,0.2,0.5 \mathrm{mg} / \mathrm{L}$ 수준으 로 무처리 시료를 이용해 희석하여 matrix matched 표준용매를 만들었고, Table 2-4의 기기분석조건에서 나타난 chromatography 상의 peak 면적을 기준으로 검량선을 작성하였다. 기기의 정량 한계를 파악하기 위해서 $\mathrm{LC}$ 에서 $0.01,0.025,0.05,0.1 \mathrm{mg} / \mathrm{kg}$, $\mathrm{LC}-\mathrm{MS} / \mathrm{MS}$ 에서는 $0.005,0.01,0.025,0.05 \mathrm{mg} / \mathrm{kg}$ 표준용액을 기기에 주입하여 $\mathrm{S} / \mathrm{N}$ ratio가 3 이상 일 때를 검출한계, 10 이 상일 때 정량한계로 설정하였다. 또한 위의 농도의 peak 면적 값을 이용해 검량선의 직선성을 평가하였다.

시험농약의 회수율 시험을 위해 무처리 시료에 표준용액 10 $\mathrm{mg} / \mathrm{kg}$ 을 이용하여 $0.1,1.0 \mathrm{mg} / \mathrm{kg}$ 수준으로 첨가하였다 $(\mathrm{n}=3)$. 표 준용액 첨가 후 무처리 시료와 혼합 후 30 분간 방치한 후 상 기의 방법으로 회수율을 산출하였다.

\section{결과 및 고찰}

\section{딸기 중 시험농약의 정량한계 및 회수율}

딸기 중 시험농약의 표준검량선을 작성하기 위해 LC 및 LC$\mathrm{MS} / \mathrm{MS}$ 를 이용하였다. 검량선의 결정계수 $\left(\mathrm{R}^{2}\right)$ 는 0.99 이상으로 양호한 직성선을 나타내었고, 시험농약의 정량한계 (limit of quantitation, $\mathrm{LOQ}$ )는 $0.005 \sim 0.05 \mathrm{mg} / \mathrm{kg}$ 수준이었다. 딸기 중 시 험농약의 회수율 결과는 70.5 98.8\% 수준이었다(Table 4).

\section{딸기 중 azoxystrobin 처리횟수에 따른 잔류특성}

농약의 관주처리 횟수에 따른 잔류량 비교를 하기 위해서 1 주 당 $100 \mathrm{~mL}$ 씩 2회 처리(수확 7-0일전 살포), 3회 처리(수확 147-0일전 살포)를 하였다. 두 처리구의 초기 잔류량은 $0.19 \sim 0.20$ $\mathrm{mg} / \mathrm{kg}$ 이였고, 처리 7일 후 초기 잔류량 대비 75 80\% 수준으로 감소한 후 14 일 후에는 모두 불검출 되었다(Fig. 1). Azoxystrobin 은 물에 대한 용해도(solubility in water)가 $6.7 \mathrm{mg} / \mathrm{L}$ 로 다른 농 약에 비해 낮고, 옥탄올-물 분배계수 $\left(\mathrm{K}_{\mathrm{ow}}\right)$ 가 2.5 로 비극성에 가

Table 3 Ionization conditions of pesticides for detection with HPLC-MS/MS

\begin{tabular}{lccccc}
\hline \hline Compound Name & MW & Precursor ion $(\mathrm{m} / \mathrm{z})$ & Quantifier & Quantifier & Ionization mode \\
\hline Clothianidin & 249.7 & 249.6 & 168.9 & 132 & Positive \\
Thiamethoxam & 291.7 & 292 & 211.1 & 181 & Positive \\
Prochloraz & 376.7 & 375.5 & 307.6 & 265.4 & Positive \\
\hline
\end{tabular}

Table 4 Recoveries of pesticides in strawberries

\begin{tabular}{|c|c|c|c|c|c|c|}
\hline \multirow{2}{*}{ Compound Name } & \multicolumn{2}{|c|}{ Average (\%) } & \multicolumn{2}{|c|}{ RSD (\%) } & \multirow{2}{*}{$\mathrm{R}^{2}$} & \multirow{2}{*}{ LOQ $(\mu \mathrm{g} / \mathrm{g})$} \\
\hline & $0.1 \mathrm{mg} / \mathrm{kg}$ & $1.0 \mathrm{mg} / \mathrm{kg}$ & $0.1 \mathrm{mg} / \mathrm{kg}$ & $1.0 \mathrm{mg} / \mathrm{kg}$ & & \\
\hline Azoxystrobin & $95.1 \pm 16.8$ & $90.6 \pm 11.3$ & 17.6 & 12.5 & 0.999 & 0.05 \\
\hline Thimethoxam & $70.5 \pm 3.2$ & $95.9 \pm 0.3$ & 4.5 & 0.3 & 0.999 & 0.005 \\
\hline Clothianidin & $76.0 \pm 3.6$ & $98.8 \pm 4.0$ & 4.7 & 4.0 & 0.999 & 0.005 \\
\hline Prochloraz & $96.9 \pm 4.8$ & $83.8 \pm 0.5$ & 4.9 & 0.6 & 0.997 & 0.005 \\
\hline
\end{tabular}




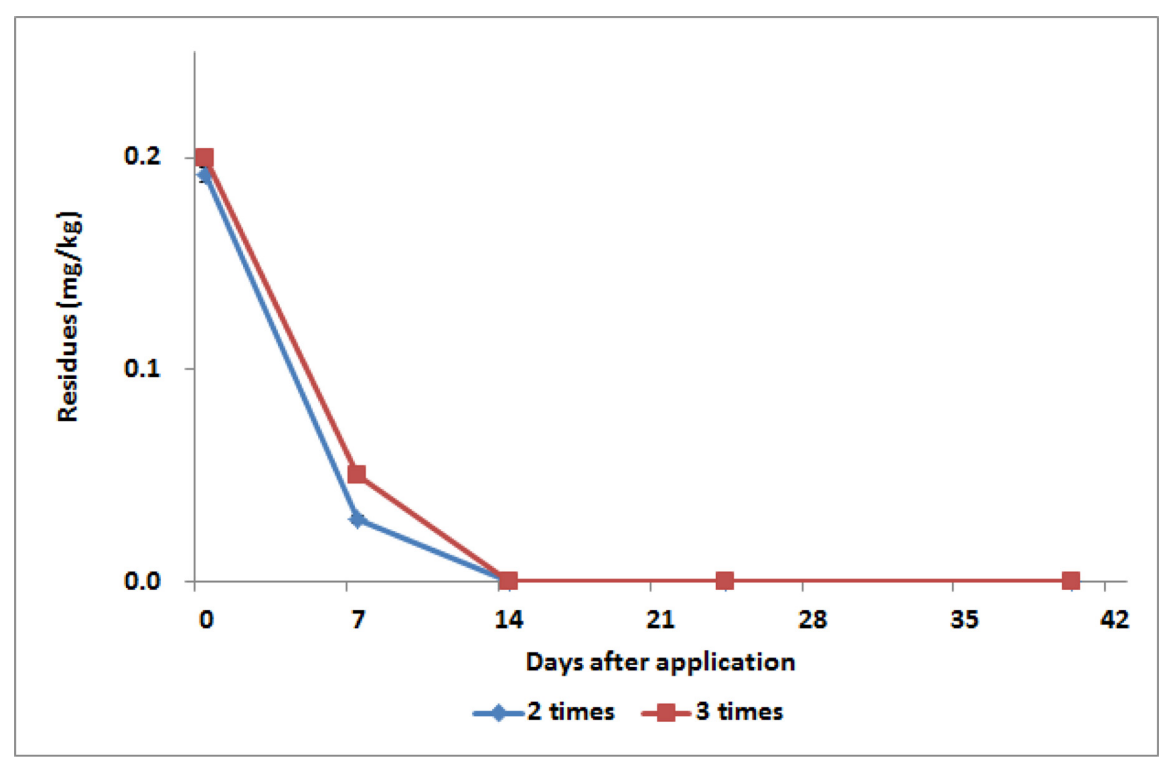

Fig. 1 Residual characteristics of azoxystrobin in strawberry by using different amount of drenchings

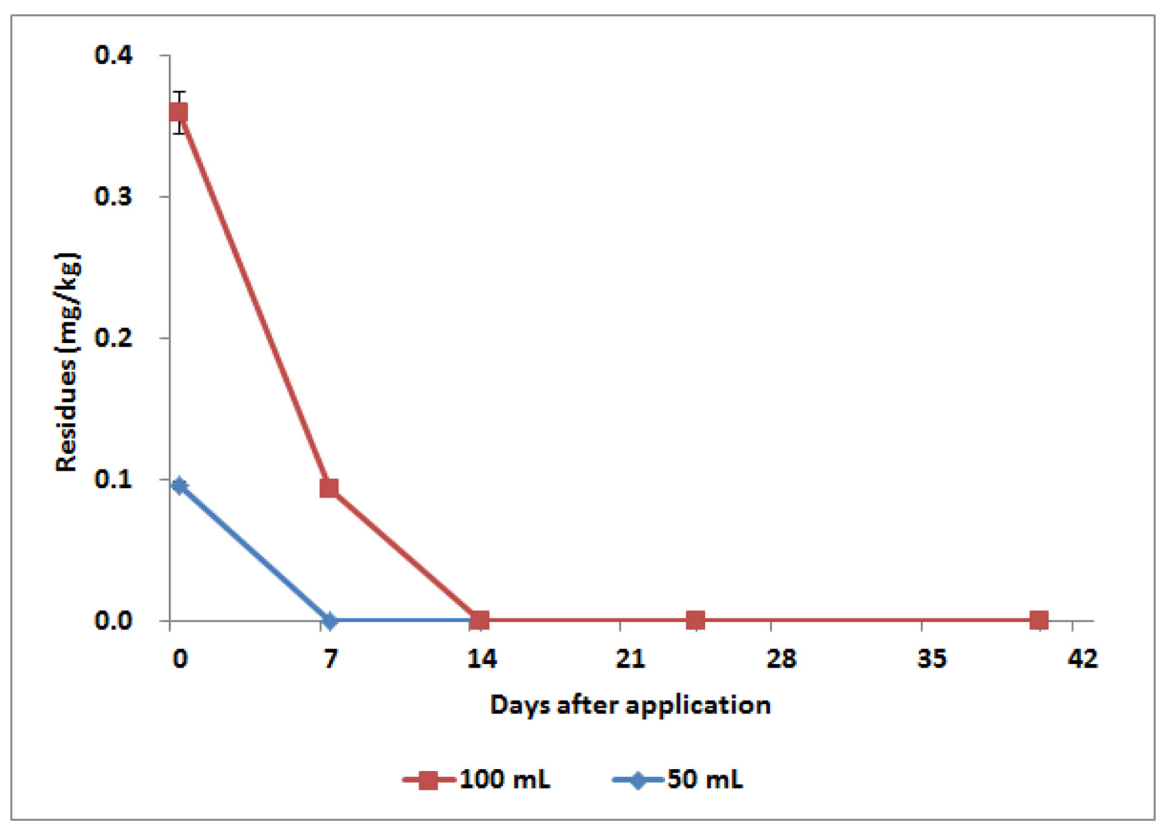

Fig. 2 Residual characteristics of prochloraz in strawberry under different quantitation of drenching

깝다(Pesticide manual). 상토 및 토양에 잔류된 농약이 작물로 이행될 때 물과 함께 가식부로 이행되는데, 위와 같은 azoxystrobin의 특성은 작물 이행에 불리하게 작용하여 잔류량 이 낮게 나타난 것으로 판단된다. Lee 등[17]의 연구에서도 azoxystrobin과 carbendazim을 관주처리 하였을 때 최대농도 수 준에서 가식부 대비 잎의 잔류량 비율이 2 3\% 정도로 나타났 다. Azoxystrobin과 carbendazim의 잎의 잔류되는 최대농도는 $5,20 \mathrm{mg} / \mathrm{kg}$ 수준으로 농약의 물에 대한 용해도에 영향이 있다 고 나타났다. 그러나 현재 azoxystrobin은 근부 탄저병 예방으 로 현장에서 관주처리하여 사용하고 있지만, 딸기에는 관주처리 약제로 등록이 되어있지 않다. Lee 등[17]의 시험과 함께 고려
하였을 때, azoxystrobin은 두 배 처리구의 3회 처리를 하여도 현재 우리나라에 설정된 MRL $(1 \mathrm{mg} / \mathrm{kg})$ 을 초과하지 않을 것으 로 판단된다. 위의 결과를 통해 딸기 중 azoxystrobin은 현재 경엽처리로 등록된 안전사용기준을 맞춰 사용하면 $\mathrm{MRL}$ 이하 로 잔류될 것으로 판단된다.

\section{딸기 중 prochloraz 살포물량에 따른 잔류특성}

딸기에 prochloraz 살포물량에 따른 잔류특성을 확인하기 위해 서 2회 처리(수확 7-0일전 살포)하였고, 살포물량을 50,100 $\mathrm{mL} /$ 주 수준으로 처리한 후 경시적 잔류양상을 확인하였다. 초 기잔류량은 $50,100 \mathrm{~mL} /$ 주 처리구에서 $0.1,0.26 \mathrm{mg} / \mathrm{kg}$ 수준으 


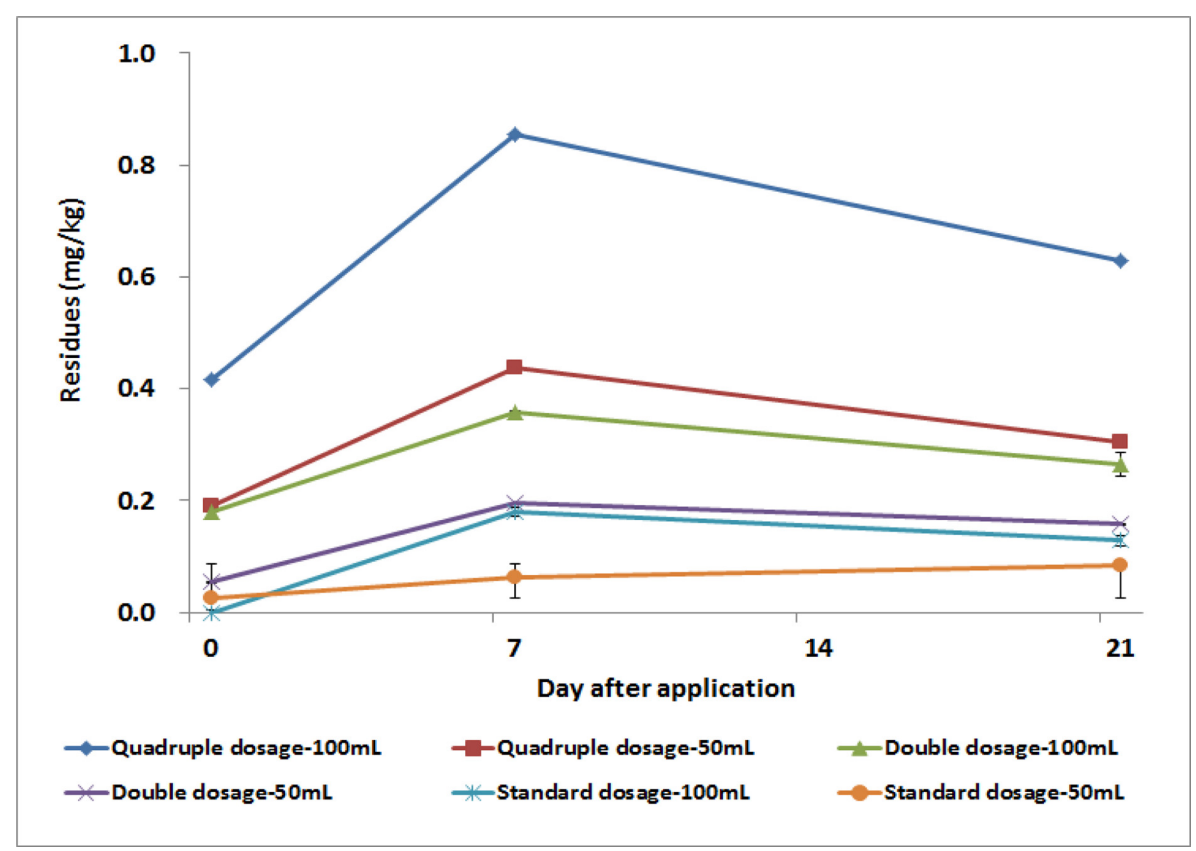

Fig. 3 Comparison of thiamethoxam residue by treatment different quantitation and dosage of drenching

로 살포물량 증가에 따라 잔류량이 증가하였고, 처리 14 일 후 에 불검출 되었다(Fig. 2). Procholraz는 물에 대한 용해도가 $34.4 \mathrm{mg} / \mathrm{L}$ 이고, $\mathrm{K}_{\mathrm{ow}}$ 가 3.53 (Pesticide manual)로 농약의 이화학 적 성질이 작물 흡수·이행이 어려운 특성을 가지기 때문에 가 식부의 잔류량이 적게 나타났다. Fang 등[18]의 연구에서도 사 과의 과육과 껍질 중 prochloraz의 잔류특성 결과에서 농약 처 리 후 $0-84$ 일 동안 잔류량은 껍질에서는 $15.3 \mathrm{mg} / \mathrm{kg}$ 에서 약 5.0 $\mathrm{mg} / \mathrm{kg}$ 사이였고, 과육은 약 $0.2 \mathrm{mg} / \mathrm{kg}$ 에서 $0.4 \mathrm{mg} / \mathrm{kg}$ 이하로 잔 류이행률이 분석시간별로 $10 \%$ 이하로 나타난 것을 확인할 수 있었다. 딸기 중 prochloraz의 관주처리 결과와 Fang 등[18] 연 구를 통해 작물체내에서 이행률이 낮은 것으로 판단된다. 농약 관주처리를 통한 작물의 잔류량은 처리횟수보다는 농약의 유효 함량에 영향을 받는 것으로 판단된다. 딸기 중 prochloraz의 1 주당 관주처리량을 다르게 하였을 때 잔류량 차이를 통하여 농 약 관주처리의 잔류량은 처리회수 보다는 유효함량 영향을 주 는 것으로 나타났다. 그러나 다른 관주처리 등록 농약의 기준 인 $100 \mathrm{~mL}$ /주와 prochloraz의 경엽살포기준인 2000배 희석 2회 살포하였을 때 prochloraz 기준인 $0.5 \mathrm{mg} / \mathrm{kg}$ 을 초과하지 않는 것으로 확인하였다.

\section{딸기 중 thiamethoxam 관주 처리시 농약 잔류특성}

딸기 중 thiamethoxam을 처리물량 $(50 \mathrm{~mL} /$ 주, $100 \mathrm{~mL}$ 주)과 희 석배수(농약안전사용기준, 농약안전사용기준의 2배, 4 배) 조건을 상이하게 하여 관주처리 한 후 경시적 잔류양상을 확인하였다. 처리횟수는 농약안전사용기준을 적용하여 2회(수확 10-0일전) 살포하였다. 딸기의 thiamethoxam 초기 잔류량은 N.D. 0.42 $\mathrm{mg} / \mathrm{kg}$ 이었고, 최대 잔류량은 최종 처리 7일 후에 0.06 0.85 $\mathrm{mg} / \mathrm{kg}$ 수준이었다(Fig. 3, Table 5). Thiamethoxam은 상토 중 에 잔류하여 계속적으로 작물로 흡수·이행 가식부의 잔류량이 증가한 것으로 판단된다. $\mathrm{Ge}$ 등[19]의 벼에서 thiamethoxam의
Table 5 Residual amount of thiamethoxam by treatment different quantitation and dosage

\begin{tabular}{ccccc}
\hline \hline \multirow{2}{*}{ Treatments } & \multicolumn{3}{c}{ Days after application } \\
\cline { 3 - 5 } & & 0 & 7 & 21 \\
\hline Quadruple & $100 \mathrm{~mL} /$ crop & 0.42 & 0.85 & 0.63 \\
dosage & $50 \mathrm{~mL} /$ crop & 0.19 & 0.44 & 0.31 \\
\hline Double & $100 \mathrm{~mL} /$ crop & 0.18 & 0.36 & 0.27 \\
dosage & $50 \mathrm{~mL} /$ crop & 0.05 & 0.20 & 0.16 \\
\hline Standard & $100 \mathrm{~mL} /$ crop & 0.00 & 0.18 & 0.13 \\
dosage & $50 \mathrm{~mL} /$ crop & 0.02 & 0.06 & 0.08 \\
\hline
\end{tabular}

흡수·이행 연구에서 $1 \mathrm{mg} / \mathrm{kg}$ thiamethoxam이 잔류된 토양에서 0-90일 동안 $\mathrm{BCF}$ (Bioconcentration factor, 작물 중 농도: $\mathrm{C}_{\mathrm{plant}}$ /토양 중 농약: $\mathrm{C}_{\mathrm{soil}}$ )를 측정하였을 때 2.0 51.7으로 높게 나타났다. 토양 중 농약이 작물에 계속적으로 축적되어 초기에 잔류량이 높아지다가, 최고농도에 도달한 후 급격하게 낮아지는 것으로 확인되었다. 또한 $\mathrm{Ge}$ 등[19]은 농약의 흡수·이행이 water solubility와 $\mathrm{K}_{\mathrm{ow}}$ 의 영향이 크다고 언급하였다. Thiamethoxam 은 물에 대한 용해도가 $4.1 \mathrm{~g} / \mathrm{L}$ 으로 다른 두 시험농약보다 높 았고, $\mathrm{K}_{\mathrm{ow}}$ 가 -0.13 으로 극성에 가까워서 딸기에서도 작물 흡수. 이행 능력이 높게 나타난 것으로 판단된다. Thiamethoxam의 대 사물질인 clothianidin은 처리 21일 후에 모든 처리구에서 검출 되었고, 잔류량은 $0.02 \sim 0.05 \mathrm{mg} / \mathrm{kg}$ 이었다(Fig. 4). 딸기 중 thiamethoxam 대비 clothianidin의 잔류량 비율은 $8.8 \sim 41.4 \%$ 로 thiamethoxam 잔류량이 낮을수록 비율이 높게 나타났다.

Thiamethoxam은 국내 MRL $(1 \mathrm{mg} / \mathrm{kg})$ 보다 홍콩 MRL $(0.5$ $\mathrm{mg} / \mathrm{kg}$ )이 낮고, 홍콩기준에 맞는 농약안전사용지침이 없어, 홍 콩으로 수출하는 딸기 농가에서 사용을 잘 하지 않는 농약이다. 현재 등록되어 있는 기준(2000배 희석, $100 \mathrm{~mL}$ /주)으로 2 회 처 


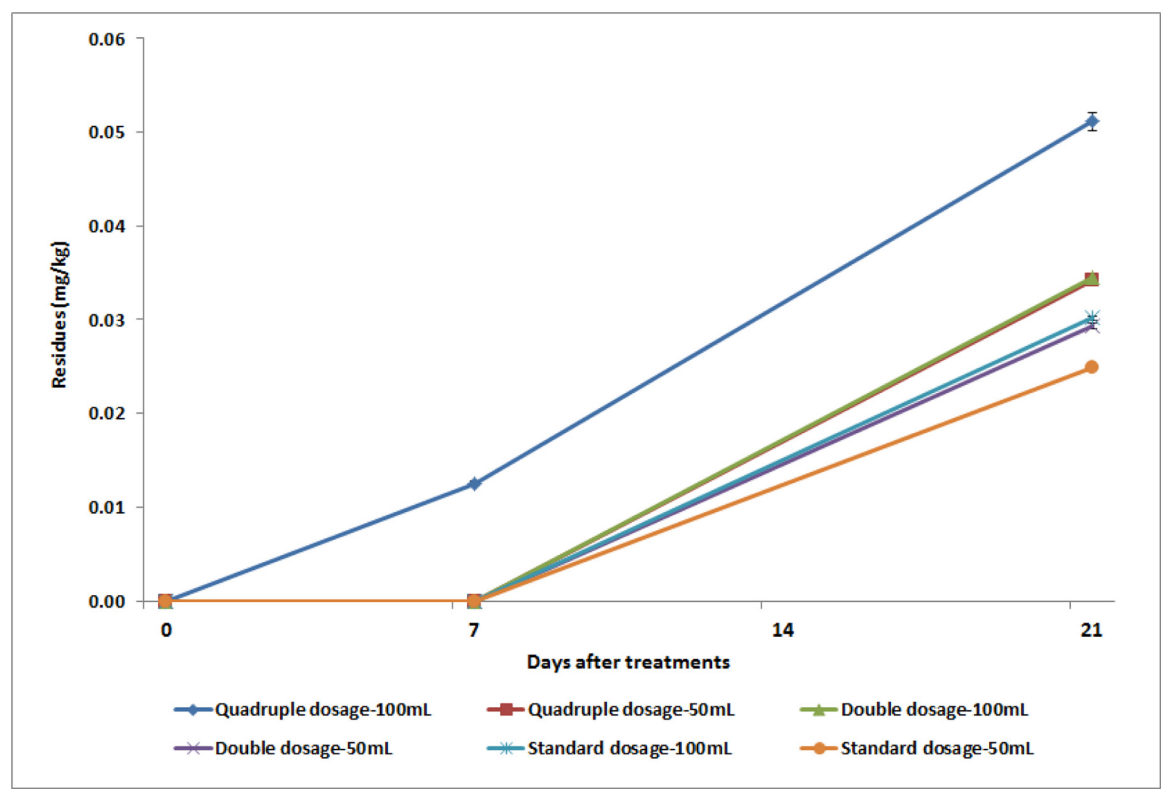

Fig. 4 Residue of clothianidin in strawberry at drenching treatment

리하였을 때 최고농도가 $0.18 \mathrm{mg} / \mathrm{kg}$ 으로 홍콩기준보다 낮아서, 현재 한국에 등록되어 있는 안전사용기준으로 살포한다면 홍콩 수출 딸기농가의 잔류안전성 문제가 없을 것으로 판단된다.

또한 위의 결과를 통해서 관주처리시 농약 잔류량은 희석배 수, 처리물량 및 처리횟수보다는 농약을 살포하는 유효함량이 가장 큰 영향이 있는 것으로 확인되었다. 같은 유효함량을 처 리한 기준처리구 $100 \mathrm{~mL}$ /주와 2배처리구 $50 \mathrm{~mL}$ /주에서 7,21일 처리구에서 유의적인 차이가 없는 것으로 나타났다. 또한 2 배 처리구 $100 \mathrm{~mL}$ 주와 4 배처리구 $50 \mathrm{~mL}$ 주에서 0,21 일차에서 잔 류량 차이가 없었다. 농약 관주처리의 안전사용기준은 경엽처리 와 달리 유효함량으로 설정하는 것이 효율적일 것으로 판단된다.

\section{초 록}

딸기는 한국의 주요 농산물 중 하나로 2017년 4,000만 달러 이 상이 수출되었다. 최근에는 양액재배를 이용해 경작하는 농가가 많아지면서 농약 관주 처리가 딸기농가에서 큰 관심을 받고 있 다. 그러나 농약 관주처리에 대한 연구가 부족하여, 현장에서는 제대로 이용되지 못하고 있다. 이번 연구에서는 관주 처리 활 성화와 안전성 향상을 위해서 딸기 중 농약살포조건을 상이하 게 하여 관주 처리 후 농약 잔류량을 경시적으로 분석하였다. 실험은 딸기에 시험농약을 상이한 조건(살포횟수, 살포량, 희석 배수)으로 관주처리한 후 azoxystrobin과 prochloraz는 0, 7, 14, 24,40 일에 분석하였고, thiamethoxam은 $0,7,24$ 일 분석하였다. 실험결과 azoxystrobin 및 prochloraz는 관주 처리하였을 때 최 종처리 14일 후에 불검출 되었고, thiamethoxam은 0.02-0.85 $\mathrm{mg} / \mathrm{kg}$ 으로 잔류하였다. 농약 관주처리시 이행량은 농약의 옥탄 올-물 분배계수와 물의 대한 용해도가 큰 영향을 미쳤다. 농약 을 관주처리 할 때 농산물 내 잔류량은 농약을 실질적으로 살 포한 유효함량에 가장 큰 영향을 받는 것으로 사료된다.
Keywords 관주처리·농약 - 딸기 · 양액재배

Acknowledgment 본 연구는 농촌진흥청 국립농업과학원 농업과학기술 연 구개발사업(과제번호: PJ01131204)의 지원에 의해 이루어진 것임.

\section{References}

1. Ayala-Zavala JF, Wang SY, Wang CY, Gonza'lez-Aguilar GA (2004) Effect of storage temperatures on antioxidant capacity and aroma compounds in strawberry fruit. Swiss Soc Food Sci Technol 37: 687-695

2. Azodanlou R, Darbellay C, Luisier J, Villettaz J, Amado R (2003) Quality assessment of strawberries (Fragaria species). J Agric Food Chem 51: 715-721

3. Cho J, Ha SD, Kim KS (2004) Inhibitory effects of temperature, pH, and potassium sorbate against natural microflora in strawberry paste during storage. Korean J Food Sci Technol 36: 355-360

4. Park KH, Kim SH (2011) A comparative study of consumer preference for strawberries in korea and singapore. Korean J Agric Manag Policy 38: $321-340$

5. RDA (2017) Export agricultural products safe use technology. Rural Development Administration Available from: http://www.nongsaro.go.kr. Accessed 12 Dec 2016

6. Kim YH, Lee IB, Chun CH, Hwang HS, Hong SW, Seo IH, Yoo JI, Bitog JP, Kwon KS (2009) Utilization of $\mathrm{CO}_{2}$ Influence by windbreak in an elevated production system for strawberry. J Bio-Environment Control 18 (1): 29-39

7. Ko IB (2015) Current Situation and Perspectives of Hydroponic System for Strawberry Cultivation in Korea. Dissertation, Konkuk University

8. Nam MH, Jeon YN, Lee HC, Lee HD, Kang HK (2012) Comparative analysis between healthy and powdery mildew-infected plants of strawberry cultivar Seolhyang. Research in Plant Disease 18 (2): 80-85

9. Ahn XH, Lee SB, An WH, Kim JD (2007) Risk Assessment of Trifloxystrobin in Chinese Cabbage by Foliar Application and Drenching. The Korean J Pestic Sci 11(1): 21-27

10. Juraske R, Castells F, Vijay A, Munoz P, Anton A (2009) Uptake and persistence of pesticides in plants: Measurements and model estimates 
for imidacloprid after foliar and soil application. J Harzard Mater 165: 683-689

11. Kim SH, Choi SY, Lim YS, Yoon JT, Choi BS (2002) Effect of chemical treatment on the control of strawberry anthracnose caused by collectotrichum sp. Rex. Plant dis 8(1): 50-54

12. RDA (2016) Export agriculture. Rural Development Administration RDA Web. http://www.nongsaro.go.kr. Accessed 12 Dec 2016

13. MARFA (2018) 2017 MARFA statistics. Ministry of Agficulture Food and Rural Affairs http://www.lib.mafra.go.kr. Accessed 10 Oct 2018

14. Kim HH, Choo HY, Lee DW, Lee SM, Jeon HY, Cho MR, Yiem MS (2003) Control efficacy of Korean entomopathogenic nematodes against fungus gnat, bradysia agrestis (Diptera: Sciaridae) and persistence in bed soil. J kor Soc Hort Sci 44(3): 393-401

15. Kwon HY, Kim CS, Park BJ, Jin YD, Son KA, Hong SM, Lee JB, Im GJ (2011) Multiresidue analysis of 240 pesticides in apple and lettuce by
QuEChERS sample preparation and HPLC-MS/MS analysis. Korean J Pestic Sci 15(4): 417-433

16. Kim JH, Kim YJ, Kwon YS, Seo JS (2016) Development of multiresidue analysis of 320 pesticides in apple and rice using LC-MS/MS and GC-MS/MS. Korean J Pestic Sci 20(2): 104-127

17. Lee HS, Hong SM, Kwon HY, Kim DB, Moon BC (2017) Comparison of residue patterns between foliar application and drenching in export strawberry. J appl Biol Chem 60(4): 313-319

18. Fang QK, Yao GY, Shi YH, Ding CC, Wang Y, Wu XW, Hua RM, Cao HQ (2017) Residue Dynamics and Risk Assessment of Prochloraz and Its Metabolite 2,4,6-Trichlorophenol in Apple. J molecules 22(10): 1-9

19. GE J, Cui K, Yan HQ, Li Y, Chai YG, Liu XJ, Cheng JF, Yu XG (2017) Uptake and translocation of imidacloprid, thiamethoxam and difenoconazole in rice plants J Environmental Pollution 226: 479-485 